\title{
Research on Development Mechanism of Tourism Industrial Cluster Based on the "Three Chains" Collaboration
}

\author{
Zhongzhi Wang $^{1} \&$ Yongqing Zhang ${ }^{1}$ \\ ${ }^{1}$ Business School, University of Shanghai for Science and Technology, Shanghai, China \\ Correspondence: Zhongzhi Wang, Development and Reform Commission of Yancheng City, 21, Century Avenue, \\ Yancheng 224005, China. E-mail: wzz75518@163.com
}

Received: April 4, 2015

Accepted: April 23, 2015

Online Published: May 17, 2015

doi:10.5430/ijba.v6n3p113

URL: http://dx.doi.org/10.5430/ijba.v6n3p113

This paper is funded by the Project "A Research on Tourism Industrial Clustering Development Strategy" of China National Tourism Administration

\begin{abstract}
It is a new research perspective to study the development mechanism of tourism industrial cluster based on the "industrial value chain", "environmental value chain", "spatial value chain", and "three chains" collaboration. In this paper, authors analyze the fundamental concepts of "industrial value chain", "environmental value chain" and "spatial value chain" of tourism industrial cluster, then build a "three chains" value matrix, and conduct a deep research on its development path. On this base, authors further probe into the internal system of tourism industrial cluster, especially lay stress on analyzing the core of tourism industrial cluster's sustainable development, i.e. the "three chains" collaboration, establish a theoretical model for "three chains" collaboration development, and discuss the development mechanism of tourism industrial cluster.
\end{abstract}

Keywords: tourism industrial cluster, development mechanism, industrial value chain, environmental value chain, spatial value chain, collaboration

\section{Introduction}

Contemporarily, theoretical researches on the development mechanism of tourism industrial cover two aspects. The first is to start from the internal of tourism industrial cluster, chiefly focusing on studying the development mechanism in perspective of the industrial value chain of tourism industrial cluster. Gollub James (2002) holds the notion that the value of tourism industrial cluster is reflected by the value chain. The tourism industrial cluster mainly consists of the three-layer value chain. The first layer is the output, composed of the tourism products and events at the tourism site. The second is the supply, composed of tourism equipments, infrastructure, and services facilities. The third is the input, composed of human resource system, products and service innovation system, financial system, information system, commercial environment, environmental quality, marketing system, etc. Jiyuan Huang (2006) agrees that the different enterprises in tourism industrial cluster take different responsibilities of value creation. The tourism industrial value chain consists of tourism supply, tourism intermediaries, and consumers. A group of upstream and downstream enterprises supply with services (products) for ultimate consumers together. Jinming Yuan, et al. (2011) analyze the essential elements of tourism industrial value chain, discuss the competitive strategy of tourism industrial value chain from three levels, i.e. tourism site (and products), industrial cluster, and tourism enterprise. They further put forward that the future competitive focus of regional tourism industrial development will change from the current competition between enterprises into the value-chain-based competition between enterprise clusters. Regional tourism enterprises, especially the leading enterprise, must adapt to the continuous transfer and change of the key value in the industrial value chain, in order to keep the critical position in the value chain and maintain the competitive advantage. By this way, the reasonable structure of industrial chain and the high collaborative efficiency can be realized, achieving the maximum interests of industrial value chain. The second is to make analysis in perspective of global value chain, which lays stress on the cross-border cooperation between tourism industrial clusters. Sara (2003) believes that various subjects clusters, such as legacy touring, special touring, adventuring and sports touring, transcend regional and administrative borders to form the team touring based on the value chain in cooperation, collaboratively providing a valuable touring experience for tourists. 
Yuyan Gai (2008) explores the integration of tourism industrial value chain based on the customer value and believes that the integrated tourism industrial chain will change from the "one-to-one" single value chain into the network mode, connecting the value chain members, including cross-border tourism suppliers, intermediaries, and tourists through the e-commerce platform, which can achieve the coordinated development of tourism industrial value chain while cultivating core touring enterprises and expanding customer values.

In general, these researches do not establish a consistent analysis frame for the development of tourism industrial cluster. Although some papers have already dig into the core field of tourism industrial cluster development mechanism (such as the presentation of tourism industrial value chain), they still fail to comprehensively reveal the fundamental laws of tourism industrial cluster development. Beizhan Yan (2011) studies the theory of clustered industrial chain upgrade and believes that the upgrading of industrial cluster-based "three chains" (product chain, knowledge chain, and value chain) is the process in which the product chain upgrade is the base, the knowledge chain upgrade the core, and value chain upgrade the objective. It is a "three chains" dynamic and interactive upgrading and transformation process. Inspired by this idea, in this paper authors conduct a research on the development mechanism of tourism industrial cluster based on theories of value chain, industrial cluster, and collaboration, in perspective of industry, environment, and space, especially focusing on tourism industrial cluster forming industrial value chain, environmental value chain, and spatial value chain, and "three chains" collaboration, integrating "transportation, sightseeing, hotel, food, purchase, and entertainment" and other tourism elements, and realizing the overall value of tourism industrial cluster. In this paper, the industrial value chain chiefly means that the tourism industrial cluster uses the value chain to realize the organic connection of "transportation, sightseeing, hotel, food, purchase, and entertainment" and other tourism elements. The environmental value chain chiefly means the value changing activities of "transportation, sightseeing, hotel, food, purchase, and entertainment" and other tourism elements of tourism industrial value chain in resources and environment. The spatial value chain chiefly means that the "transportation, sightseeing, hotel, food, purchase, and entertainment" and other tourism elements in certain space develop into the tourism industrial cluster through industrial value chain and environmental value chain, depending on cooperation and collaboration to provide value-added touring services, and achieving the sustainable development of tourism industrial cluster.

In practice, a group of competitive tourism industrial clusters have emerged in the Yangtze River Delta, Hainan, Jiuzhaigou, and Xi'an, and other areas, where well illustrates the development of industrial value chain, environmental value chain, spatial value chain, and "three chains" collaboration, which provides a good application platform for the study of the "three chains" collaboration of tourism industrial cluster.

By means of literature collection, summarizing, logical deduction, comparative analysis, model building, and other research methods, this paper explores the basic concepts of tourism industrial cluster's "industrial value chain", "environmental value chain", "spatial value chain", and "three chains" collaboration, as well as the development path, the theoretical model of "three chains" collaboration development, and discusses the core of tourism industrial cluster's sustainable development, namely the interactive mechanism of "three chains" collaboration. However, due to the technical difficulties of quantitative analysis and the pioneering nature of the research, some problems need to be tackled in further studies.

\section{The "Three Chains" Development Path for Tourism Industrial Cluster}

We categorize the industrial value chain, environmental value chain, and spatial value chain of tourism industrial cluster in accordance with the value chain matrix (VC matrix) and deduct its development path. The VC matrix is an extension of Boston VC matrix. Abstract the dominant influencing elements vertically and horizontally from the industrial value chain, environmental value chain, and spatial value chain. Develop a matrix in a two-dimensional matrix axes and analyze the "three chains" organization.

\subsection{The Industrial Value Chain of Tourism Industrial Cluster}

\subsubsection{The Types of Industrial Value Chain of Tourism Industrial Cluster}

According to the integrity of local industrial chain (horizontally) and the industrial concentration (vertically), we classify the industrial value chain of tourism industrial cluster into four types (see to Figure 1). 


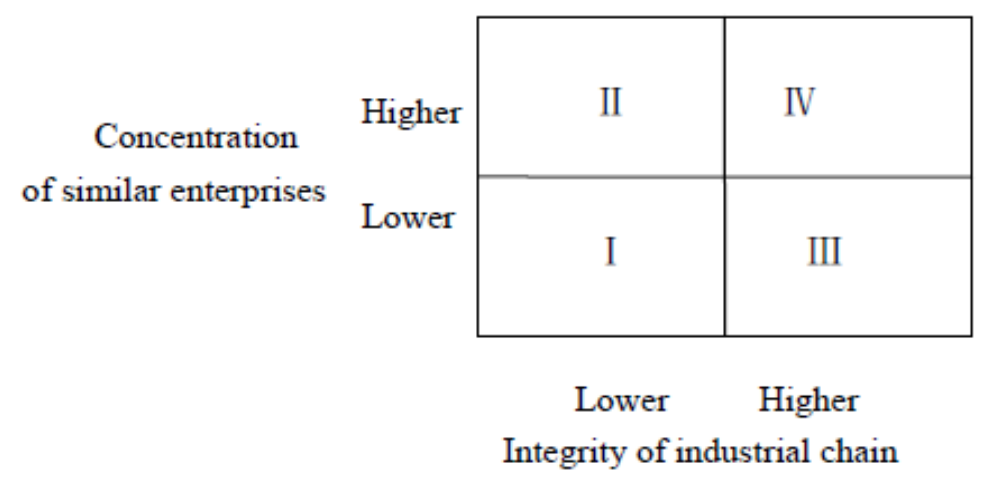

Figure 1. The types of industrial value chain of tourism industrial cluster

The industrial value chain of tourism industrial cluster, type I: lower integrity and lower concentration. Horizontally, there is certain relationship between upstream and downstream enterprises in tourism industrial chain, but lacking close cooperation. Vertically, there is few similar enterprises and especially in shortage of large enterprises. Early development of the tourism industrial cluster often belongs to this type.

The industrial value chain of tourism industrial cluster, type II: lower integrity, higher concentration. There are many similar enterprises. Driven by one or several large enterprises, the upstream and downstream enterprises will follow up.

The industrial value chain of tourism industrial cluster, type III: higher integrity, lower concentration. Although there is few similar enterprises and lack of large enterprise, the inter-dependence is relatively strong between upstream and downstream enterprises.

The industrial value chain of tourism industrial cluster, type IV: higher integrity, higher concentration. There is close cooperation of one or several large enterprises in "transportation, sightseeing, hotel, food, purchase, and entertainment", and also the friendly interaction between large enterprises and similar small and medium-sized enterprises.

2.1.2 The Development Path for the Industrial Value Chain of Tourism Industrial Cluster

Path 1: I $\rightarrow$ II $\rightarrow$ IV. From type I to type II: attract external large enterprises to enter and improve the concentration of similar enterprises; from type II to type IV: after the external large enterprises entering, it triggers the regional concentration of similar enterprises and upstream and downstream enterprises, which further develops lots of equipped enterprises, forming a complete tourism industrial value chain.

Path 2: I $\rightarrow$ III $\rightarrow$ IV. From type I to type II: extend the tourism industrial chain upward and downward, and continue to improve the integrity of regional tourism industrial chain; from type III to type IV: encourage large enterprises or competitive medium-sized enterprises to merge other similar enterprises to form a group. The emergence and development of large enterprises will strengthen the growth of tourism industrial cluster and increase the concentration of similar enterprises.

\subsection{The Environmental Value Chain of Tourism Industrial Cluster}

\subsubsection{The Types of Environmental Value Chain of Tourism Industrial Cluster}

There are two-way impacts between tourism industrial cluster and environment. The environmental value includes product environmental value and capacity environmental value. For the environmental value chain of tourism industrial cluster, the levels of product environment (horizontally) and the forces of social environmental network (vertical) are two critical factors affecting the cluster environment.

In perspective of the levels of product environment, levels can be distinguished by the attractiveness and the differences of the touring place. The social environmental network can be observed from the bearing capacity and the inclusiveness. Thus, we classify the environmental value chain of tourism industrial cluster into four types (see Figure 2). 


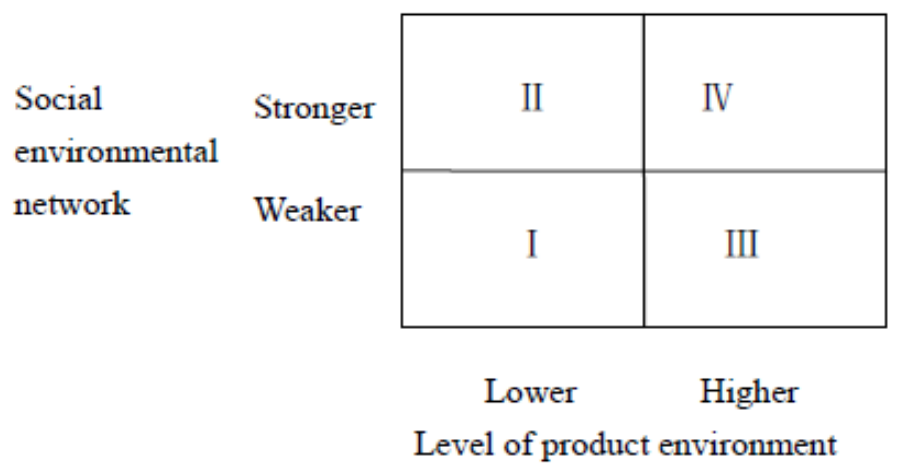

Figure 2. The types of environmental value chain of tourism industrial cluster

The environmental value chain of tourism industrial cluster, type I: weaker social environmental network and lower product environmental level. It is a low-level environmental value chain of tourism industrial cluster. The early period of some country tourism industrial clusters often falls into this type.

The environmental value chain of tourism industrial cluster, type II: stronger social environmental network and lower product environmental level. With the growth of environmental bearing capacity and inclusiveness, the size of tourism industrial cluster increases, and the social environmental network continues to expand. However, because of the lower product environmental level, the tourism industrial cluster lacks of core competitiveness.

The environmental value chain of tourism industrial cluster, type III: weaker social environmental network and higher product environmental level. Through repairing, improving, and enhancing the social environment, the level of product environment can be further upgraded.

The environmental value chain of tourism industrial cluster, type IV: stronger social environmental network and higher product environmental level.

\subsubsection{The Development Path for Environmental Value Chain of Tourism Industrial Cluster}

Path 1: I $\rightarrow$ II $\rightarrow$ IV. From type I to type II: use other organizations' power to improve the social environmental network's bearing capacity and inclusiveness; from type II to type IV: the expansion of social environmental network of tourism industrial cluster provides spaces for improving the level of product environment, which can effectively drive the tourism industrial cluster from the low end to the high end.

Path 2: I $\rightarrow$ III $\rightarrow$ IV. From type I to type III: large enterprises' input can effectively improve the level of product environment; from type III to type IV: touring enterprises cooperate with local government, communities, and residents actively, further improving the social environment.

\subsection{The Spatial Value Chain of Tourism Industrial Cluster}

\subsubsection{The Types of Spatial Value Chain of Tourism Industrial Cluster}

The construction of spatial value chain of tourism industrial cluster is affected by two factors. The first is the added value of internal tourism industrial cluster (horizontally); the second is the time distance between tourism industrial clusters (time distance, i.e. the spatial distance measured by walking time, here it means the transportation time and distance between tourism industrial clusters. With fixed geological distance, the fewer the transportation time is, the better it is; vertically). From the cluster distribution of spatial value chain of tourism industrial cluster, in certain specific area, not all clusters have the same amount of value creation. Generally speaking, the surrounding tourism industrial clusters gain relatively less profits, whereas the core tourism industrial clusters gain more. Thus, classify the spatial value chain of tourism industrial cluster into four types (see Figure 3). 


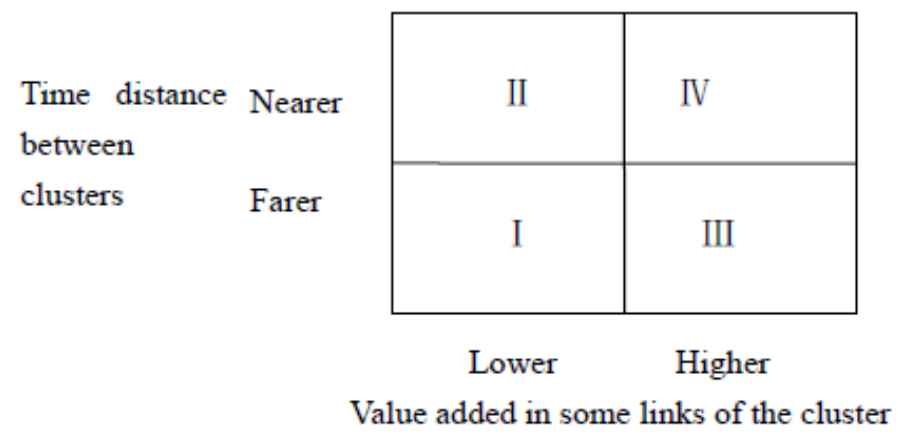

Figure 3. The types of spatial value chain of tourism industrial cluster

The spatial value chain of tourism industrial cluster, type I: farer time distance, and lower added value. The early stage of spatial value chain of country tourism industrial cluster belongs to this type, since the profitability is poor.

The spatial value chain of tourism industrial cluster, type II: nearer time distance, and lower added value. A complementary development between surrounding tourism industrial clusters and core clusters does not well developed. The value is increasing at a lower level.

The spatial value chain of tourism industrial cluster, type III: farer time distance, and higher added value. Scenic zones with great mountains belong to this type.

The spatial value chain of tourism industrial cluster, type IV: nearer time distance and higher added value. Urban tourism industrial clusters often fall into this type.

\subsubsection{The Development Path for Spatial Value Chain of Tourism Industrial Cluster}

Path 1: I $\rightarrow$ II $\rightarrow$ IV. From type I to type II: the distance between different tourism industrial clusters is shortened due to the progress of transportation, which improves the collaboration of clusters in a sense. The interdependence is growing. From type II to type IV: with the gradual integrity of spatial value chain, the "transportation, sightseeing, hotel, food, purchase, and entertainment" of tourism industrial cluster continues to achieve added value.

Path 2: I $\rightarrow$ III $\rightarrow$ IV. From type I to type III: considering the regional tourism industrial cluster, local government accelerates the formation of core regional tourism industrial cluster, promoting the growth of spatial value chain's added value. Form type III to type IV: with the development of spatial value chain, surrounding tourism industrial clusters and core tourism industrial clusters achieve close cooperation, and further form one or several complete spatial value chains. Each chain grows with increasing added values.

\section{The Development Mechanism of "Three Chains" Collaboration of Tourism Industrial Cluster}

Currently, in discussing the development mechanism of tourism industrial cluster, quite a lot literatures analyze the industrial value chain consisted by upstream and downstream enterprises, or focus on the industrial value chain in the global value chain. We hold the notion that the sustainable development of tourism industrial cluster needs to build the industrial value chain, environmental value chain, and spatial value chain. The critical point is to achieve the collaboration of industrial value chain, environmental value chain, and spatial value chain. We take references from Porter's Diamond Model as we establish the "three chains" of tourism industrial cluster and the theoretical model of their collaboration (see Figure 4). For the three chains of tourism industrial cluster and their collaboration, the precondition is the market demand and the core is the interaction of industrial value chain, environmental value chain, and spatial value chain. Through continuously increasing the value of tourism industrial cluster, it can achieve the sustainable development of tourism industrial cluster. This model includes four basic factors, i.e. market demand, industrial value chain, environmental value chain, and spatial value chain, and two group of assisting factors, i.e. opportunities and public policies. 


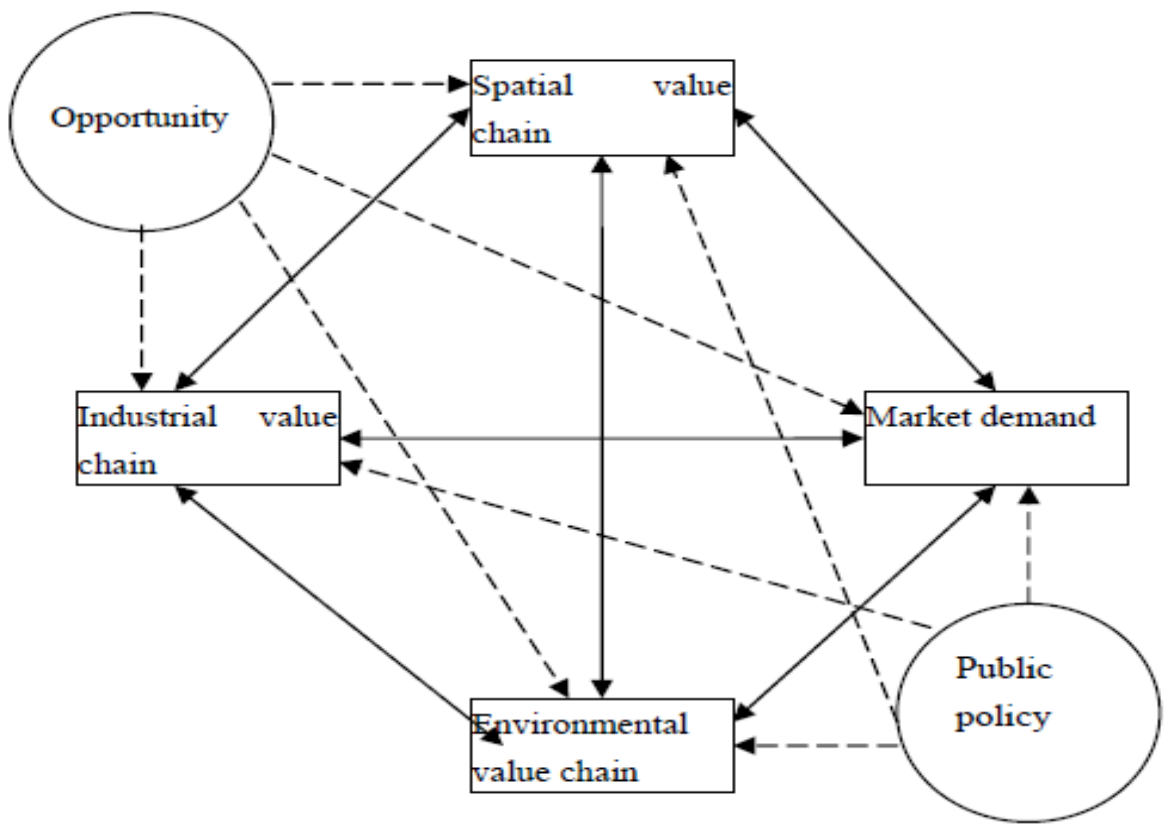

Figure 4. The theoretical model of tourism industrial cluster's "three chains" and its collaboration

In the perspective of "three chains" system, the "three chains" and their collaboration are the core mechanism promoting the sustainable development of tourism industrial cluster. The main function is to turn tourism industrial cluster's core elements and resources into competitive advantages through the movements of "three chains" and their interactive collaboration. The more powerful the function of tourism industrial cluster's "three chains" system, the stronger the tourism industrial cluster's competitiveness is. The sustainable development tourism industrial cluster will be accomplished by the dynamic mechanism of three chains collaboration. We sort the dynamic mechanism of "three chains" system into internal and external dynamic mechanism. The internal dynamic mechanism, including market demand, labor division and cooperation, economy of scope, and economy of scale, are the essential forces promoting the sustainable development of tourism industrial cluster. The external dynamic mechanism is chiefly derived from external existence and development environment, including government promotion, development opportunity, and regional culture. The internal and external dynamic mechanisms drive the tourism industrial cluster's "three chains" system to achieve collaboration, further improving the capability of utilizing elements and resources. Besides, all stakeholders continuously update or obtain more valuable elements and resources, testing and giving feedback to the tourism industrial cluster's competitive advantages in practice, guiding the optimization and adjustment of "three chains" collaboration mechanism, and ultimately achieving the evolvement and sustainable development of tourism industrial cluster.

\subsection{The Law of Market Demand Promoting Industrial Chain, Environmental Chain, and Spatial Chain}

The market demand, especially the domestic market demand, is the basic impetus for the sustainable development of tourism industrial cluster. At the early stage of tourism industrial cluster, in the process of touring enterprises identifying and satisfying the domestic customers' needs, the tourism industrial value chain gradually comes into being. Meanwhile, engaged in the social environment and product environment, touring enterprises try to satisfy the expected market demand, especially the demand for ecological products, which further triggers the competitive advantages of tourism industrial cluster. Under the influence of the spillover effect of market demand value, the expansion of one tourism industrial cluster or the merge of several tourism industrial clusters in a specific area will be carried out. The tourism industrial cluster enters the path of sustainable development.

\subsection{The Law of Industrial Chain Promoting the Environmental Chain and Spatial Chain}

The development of industrial chain is the process of improving the concentration of similar enterprises and the integrity of tourism industrial chain. On one hand, with the improvement of concentration of similar enterprises, especially under the leadership of large enterprises, not only the social environment and product environment is upgraded, but new industrial chain can also appear. It can drive the constitution and development of spatial chain 
through a spread mechanism, and achieve more added values by integrating industrial chain. On the other hand, the improvement of the integrity of tourism industrial chain is the process of tourism enterprises choosing cooperation and forming network, and also a process of the industrial chain changing from a loose type into a tight one. It not only satisfies the market demand effectively, but also benefits the formation of a complete spatial chain, which further drive the tourism industrial cluster to develop from the low value added stage toward the high value added stage.

\subsection{The Law of the Environmental Chain Promoting the Industrial Chain and Spatial Chain}

The development of environmental chain is a process in which the social environmental network is strengthened and the product environmental level is improved. On one hand, to strengthen the social environmental network means continuously expanding social environment's bearing capacity and inclusiveness. More and more touring enterprises seize the development opportunities and public policies and promote the extension of the integrity of tourism industrial value chain, accelerating the development of spatial chain. On the other hand, the improvement of product environmental level can enhance the core position of large enterprises in the spatial chain through the sharing mechanism, promoting the improvement of the concentration of similar enterprises in industrial chain.

\subsection{The Law of the Spatial Chain Promoting the Industrial Chain and Environmental Chain}

The development of the spatial chain is a process in which the added value part of the tourism industrial cluster is improved and the time distance between clusters is adjusted. On one hand, the added value continues to rise. It promotes the development of the integrity of industrial value chain in the core regional clusters through the interaction of spatial chains, achieving the enhancement of social environmental network. On the other hand, the adjustment of time distance between tourism industrial clusters results in stronger congregation effect of spatial chains, promoting touring enterprises' growth and collection. Other tourism industrial clusters may choose to merge, which can help to improve the product environmental level.

\subsection{The Law of the Assisting Factors Promoting the Fundamental Factors}

The government public policies have significant effects on the development of tourism industrial cluster. The government can provide the necessary resources, develop favorable environment, make significant investment, create market demand, and further strengthen the sustainable development of tourism industrial cluster. The development opportunity is unpredictable. Only by seizing development opportunity, can the cluster satisfy the market demand and achieve further development.

Therefore, driven by the public policy and development opportunity, the "three chains" of tourism industrial cluster must focus on market demand. The development of any chain will result in the development of the other two. As the tourism industrial cluster is engaged in some initial activities, the industrial chain transforms frequently on the development path. Under this influence, the environmental chain and spatial chain of tourism industrial cluster connect with the industrial chain and drive the transformation of three of them. By this way, it can achieve the eternal development of entire tourism industrial cluster.

\section{Conclusion}

By referencing previous researches and studies, based on practical conditions, in this paper authors choose the sustainable development mechanism of tourism industrial cluster as the research angle, comprehensively adopt different disciplines, including industrial economics, geographical economics, management, and ecology, propose the concepts of "industrial value chain", "environmental value chain", and "spatial value chain" of tourism industrial cluster for the first time, and conduct a deep analysis on the core of the cluster's sustainable development, i.e. the "three chains" and their collaboration mechanism. The above discussion and research fill the theory blank of the tourism industrial cluster. Especially under the background of the transforming and upgrading of domestic tourism industrial cluster, this research offers some thoughts and theoretical basis for local governments constituting and executing the policy for the eternal development of tourism industrial cluster.

The concepts of "industrial value chain", "environmental value chain", and "spatial value chain" of tourism industrial cluster and the analysis on the "three chains" and their collaboration mechanism, as well as the model, are still immature. They need to be further improved and studied. In addition, how to comprehensively use multiple empirical research methods, such as mathematical modeling, and case study, to testify the rationality of the model, the features of the "industrial value chain", "environmental value chain", and "spatial value chain" of tourism industrial cluster based on heterogeneity and their development mechanism deserve further in-depth discussion. 


\section{References}

Gai, Y.Y. (2008). A study of tourism value chain integration based on the customer value. Heilongiiang Social Sciences, (3), 79-82.

Huang, C., \& Fu, Z.P. (2003). A typology of industrial clusters in the Pearl River Delta Area. Management Review, (6), 61-63.

Huang, J.Y. (2006). The competition and corporation of tourism enterprises in the tourism value chain. Inquiry into Economic Issues, (9), 99-103.

James, G., Hosier, A., \& Grace, W. (2002). Using Cluster-Based Economic Strategy to Minimize Tourism Leakages. California: SanFrancisco, p.1-59.

Sara, N. (2003). Tourism Clustering\& Innovation-Path to Economic Growth\& Development. E-tour, Sweden: Sweden University.

Yan, B.Z. (2011). The upgrade mechanism of cluster industry chain based on the advancing process of three chains. Science Research Management, (10), 64-70.

Yuan, J.M., \& Zhong, Y.D. (2011). Research on the tourism industry competitiveness based on the value chain theory: with the example of Hunan Province. Ecological Economy, (4), 125-131. 